\title{
Nova does not mean "it doesn't go".
}

The marketing myth persists that the Chevy Nova did not sell well in Latin America because "no va" means "doesn't go" en Español.

But the Nova legend is a lie -- a tenacious one at that. In fact, the car sold quite well in Latin America where Spanish-speaking consumers did not make the connection between Nova and "no va". Snopes documents the proof and Mark Liberman of Language Log refutes "false factoids" such as the alleged failures of the Chevy Nova and other brand names.

Although the story is fiction, it's irrefutable fact that Nova and "no va" are strikingly close. But close is no cigar.

Apparently, even minor differences in spelling, sound or stress will distinguish two nearly-identical words. In this case, Spanish "no va" is two words and is accented on the second syllable. Just one space and a different pronunciation insulate Nova from "no va", as the word "legend" does not make people think of "leg" and "end".

It's now known that GM was aware in advance about Nova's "doesn't go" issue, yet decided to go with it anyway. If you were in GM marketing and learned before launch that Nova sounds like "no va", would you reject it?

It'd be hard not to. After all, they're nearly identical!

The whole point of a native speaker check (sometimes called a "cultural-linguistic check") is ostensibly to root out names with inappropriate foreign language associations, so how could a whopper like Nova/"no va" slide?

Yet slide it did. And in the end, Nova did just fine in Latin America.

Stranger than the fiction of a GM flub, is the truth that a brand name and its nearhomonym remain distinct in the mind.

This phenomenon presents us with a native speaker check conundrum:

\section{How can red flags and red herrings be distinguished?}

Which inappropriate foreign associations represent true problems and which are false alarms -- all bark and no bite?

I've compiled here principles and practices to make sense of native speaker checks and their nuances. 


\section{Native Speaker Check Principles in Practice}

1. A native speaker check should be separate from other name validation research.

An accurate observation of potential foreign language issues should be the singular objective of a native speaker check. This limits confounding variables.

2. Ask a sufficient number of native speakers.

Several respondents helps distinguish idiosyncratic associations from those widely shared. I've found that three, independent respondents are sufficient.

3. Determine the right languages.

These are the usual suspects for most "global" naming projects:

French (Europe and Canada)

Italian

German

Spanish (Europe and Latin America)

Portuguese (Europe and Latin America)

Mandarin

Cantonese

Japanese

This can be expanded as appropriate to include other languages, but the task becomes more difficult and costly as the number of names and languages increase.

Multinational organizations have to weigh a cost-benefit equation. To save costs, most companies will check only a standard version of a language but not minor dialects; Standard German: yes; Swiss German: no. 


\section{Ask for observations, not opinions.}

You need to know specific and detailed information about the foreign words or phrases that resemble your name candidates. Do not ask foreign speakers about which they "like". Your questions to respondents should elicit observations, not opinions.

Here is a sample set of questions:

- How will this word be pronounced by a native speaker of your language?

- Is the word similar in sound or appearance to other words in your language? If so, what are those words, how are they pronounced, and what do they mean?

- Is the word similar to other brands in your country? If so, what brands?

- Are there any inappropriate associations that a native speaker of your language might have with this word? If so, what exactly are those associations and why would they be associated?

- Do you, as a native speaker of the language, find this word relatively easy or difficult to say? If it's relatively difficult, what sounds in the word make it difficult?

The answers reveal more than name associations. They also detail the proximity in sound and spelling to the foreign word associations. This information will help you judge the results.

That's the hard part of native speaker checks: Interpreting the data and making the right judgment calls.

\section{Evaluating Native Speaker Checks}

Consider these factors to strengthen your judgment of native speaker responses:

- How similar are the name and its associations in sound and spelling?

Pay close attention to those identical.

- How prevalent are the name associations among respondents?

If every participant has the same association, it's more likely -- though not certain -- to be widespread after launch.

- How important is the market where the name might be a problem?

Maybe it doesn't matter that your brand means "ugly" in Igbo.

- What's the culture in the country where the name could pose a problem? 
An inappropriate association might be acceptable in one country but not another. Native French speakers, in my experience, make naughty name associations so predictably, I wonder if such skills are a point of national pride, like the Eiffel Tower or cream sauces. Francophone responses I take with a grain of sel. In China, less tolerance and preponderance of negative associations makes them more damning.

- Will the name inspire marketing communications that divorce it from unwanted associations?

When Wii and Banana Republic launched, communications were built around their names. Wii's anthropomorphized vowels bowed in animation to help set it apart from "wee (wee)". Banana Republic deflected pejorative associations by silkscreening jungle critters on t-shirts bearing their name.

- Is the name also a real word in English?

If so, negative associations are more likely to be overlooked. English has name cachet in many countries.

- What's the product category?

Offensive associations are more damning for food, beverage and personal-care product names than for electronics, software and other things we don't put in or on our bodies. And mom won't buy children's products with names connoting danger or risk.

- Who's the customer?

Play it safe with names intended for audiences with conservative or traditional values. This applies to geographic segments (e.g. the Mid-East), demographic ones (e.g. the elderly) and certain industries (e.g. insurance). Some audiences are attracted by controversial or contrarian names. And unlike adults, kids are undaunted by gross-out food names like Garbage Pail Kids, White Chocolate Maggots, and booger-flavored jelly beans; just don't expect Mom to pick them up on the way home.

\section{The Positivity Principle}

These details will inform your decision, but they might not make it easy. A mitigating factor I call the "positivity principle" complicates matters -- but also illuminates why the name Chevy Nova wasn't actually a problem in Latin America.

The Positivity Principle:

When people see a brand name in the real world -- on a sign, package or business card -they assume it's intended it to be perceived positively. 
When a proposed name is seen the context of a native speaker check or naming research - when names are presented as hypothetical or speculative -- the positivity principle doesn't manifest so negative associations are easily triggered. Prospective names do not yet have validity conferred upon them because a company has not yet adopted them.

Imagine how Virgin, Motley Fool, Yelp, Alibaba, the Gap and Bazooka gum would have been excoriated as part of an English native speaker check. Yet, as living brands, they evade obvious, unflattering associations.

These names are given the benefit of the doubt because (1) they have already been adapted and launched by companies and (2) they harbor positive and relevant connotations that divert attention from negative denotations:

- Virgin symbolizes the philosophy of conducting business as it's never been done;

- A Motley Fool was the only one who'd tell the king the truth;

- Yelp undergoes a semantic shift from denoting a cry of pain, to connoting an impassioned proclamation

\section{Limits of the Positivity Principle}

The positivity principle has limits: You can't just go and adopt offensive names willynilly expecting they'll be warmly received by everyone.

The positivity principle does not seem to benefit a name whose negative connotations have no conceivable positive relevance to its product. For instance:

\section{Calpis}

This Japanese beverage is marketed as Calpico in the States because the original name sounds very close to "cow piss". When you're selling an unfamiliar, foreign beverage at retail, it's best to avoid anything disgusting.

\section{Reebok Incubus}

Apparently Reebok didn't know that this is a demon that attacks women in their sleep. If Reebok had, this word wouldn't have been used as the name for a short-lived women's running shoe.

True naming blunders like the Reebok Incubus are rare, though it might not seem so. Infamous naming gaffes are retold again and again in the media, belying their actual rarity. Yet the examples typically trotted out for public pillory -- Chevy Nova, Ford Pinto, et al. -- are pure fiction. 


\section{How Red Herrings Become Red Flags}

In the end, it might not matter that a brand can be a bad word in foreign dictionary and yet be a good name to those foreign customers. If enough journalists mock the moniker, it could turn a red herring into a red flag. International name problems, even imagined or manufactured ones, are still problems. The public's perception will become a company's reality.

A native speaker check can help a company make a fully-informed name decision. But it is just one data point, and one which can easily mislead. The greatest risk to a business might not be the adoption of a potentially offensive name, but the rejection of a truly great one.

I hope the principles and practices I've outlined here will help you distinguish native speaker red herrings from red flags.

Just remember to:

Ask the right questions...

listen closely to the answers...

then, on occasion, ignore them.

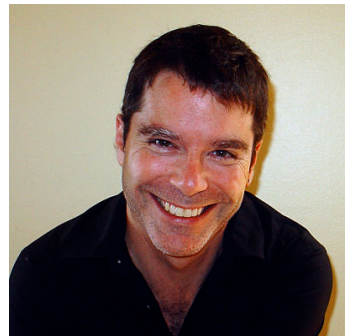

Anthony Shore helps companies define and name new brands. With 20 years international experience, Anthony has introduced over 120 product and company names to the world. He's Chief Operative of Operative Words, and former Global Director of Naming and Writing for Landor Associates. Anthony created or lead the creation of corporate names like Accenture, Yum Brands and Scribe Winery; and products such as Soyjoy Nutrition Bars, Qualcomm Snapdragon and Autodesk Homestyler. Experienced as a global marketer, strategist, software product manager, designer and copywriter, he brings a holistic perspective to verbal branding programs. Anthony has appeared in The Wall Street Journal, USA Today, CNET and The Economist. He received his Linguistics degree with Honors from UC Santa Cruz. Anthony writes about the principles and practice of brand naming at OperativeWords.com.

This article was uploaded to http://www.languageatwork.eu in December of 2010 and published under a "Creative Commons license Attribution Non-commercial No derivatives (cc by-nc-sa)" for more information please go to: http://creativecommons.org/about/license/ 